\title{
Ontogenia dos Nectários Extraflorais de Triumfetta semitriloba (TILIACEAE) ${ }^{1}$
}

\author{
Extrafloral Nectary Ontogeny of Triumfetta semitriloba (Tiliaceae)
}

\author{
LEITÃO, C.A.E. ${ }^{2}$, MEIRA, R.M.S.A. ${ }^{3}$, AZEVEDO, A.A. ${ }^{3}$ e ARAÚJO, J.M. ${ }^{4}$
}

\begin{abstract}
RESUMO - Triumfetta semitriloba é uma planta daninha que apresenta nectários florais e extraflorais, sendo os últimos visitados por formigas que protegem a planta do ataque de insetos. O presente trabalho teve como objetivo descrever a ontogenia dos nectários extraflorais de T. semitriloba. Para isso, amostras de nectários em quatro estádios de desenvolvimento foram obtidas de plantas adultas, sendo o material submetido às técnicas usuais de obtenção de lâminas permanentes. Os nectários iniciam o seu desenvolvimento precocemente, com o surgimento de uma concavidade voltada para a face adaxial. Posteriormente, células protodérmicas dão origem a tricomas nectaríferos clavados, e subjacente se desenvolve um parênquima nectarífero vascularizado por floema e xilema, características comuns em nectários encontrados entre as Malvales. As células da cabeça dos tricomas nectaríferos apresentam vacúolos com compostos fenólicos, que possivelmente desempenham papel ecológico. Plastídios não ocorrem nos tricomas e são inconspícuos no parênquima nectarífero, o que possivelmente indica a sua importância secundária na secreção do néctar. O nectário senescente apresenta relativamente menos tricomas nectaríferos, que são penetrados por hifas de fungos que recobrem a concavidade nesse estádio. Para entendimento dos processos de secreção e eliminação do néctar, são necessários estudos ao microscópio eletrônico de transmissão.
\end{abstract}

Palavras-chave: ontogenia, nectários extraflorais, planta daninha, Tiliaceae.

ABSTRACT - Triumfetta semitriloba is a weed displaying floral and extrafloral nectaries, the latter being visited by ants that protect the plants. The objective of this work was to describe the ontogeny of the extrafloral nectaries of $\boldsymbol{T}$. semitriloba, using nectary samples obtained from adult plants, in four developmental stages. The material was submitted to the usual techniques to obtain permanent slides. The nectaries initiate their development precociously, with the appearance of one concavity turned to the adaxial side, followed by clavated nectariferous trichomes, originated from protodermic cells, underlied by a nectariferous parenchyma vascularized by phloem and xylem, which are common features among the Malvales. The nectariferous trichome head cells present vacuoles with phenolic compounds, which may play an ecological role. Plastids are absent in the trichomes and are not conspicuous in the nectariferous parenchyma, possibly indicating their secondary importance in nectar secretion. The senescent nectary has relatively less nectariferous trichomes, which are invaded by hyphae covering the concavity at this stage. For a better understanding of the processes of nectar secretion and elimination, further transmission electronic microscope studies are needed.

Key words: ontogeny, extrafloral nectaries, weed, Tiliaceae.

\section{INTRODUÇÃO}

Nectários são estruturas secretoras de néctar que ocorrem na superfície de vários órgãos vegetais (Fahn, 1979). O néctar é uma solução composta, basicamente, por sacarose, glicose e frutose nas mais variadas concentrações, podendo conter, ainda, diversas outras

1 Recebido para publicação em 24/4/2002 e na forma revisada em 9/12/2002.

Parte da tese do primeiro autor, financiada pelo CNPq e pela CAPES.

2 Aluno do Programa de Mestrado em Botânica da Universidade Federal de Viçosa - UFV, <candre@ bol.com.br>; ${ }^{3}$ Professores do Dep. de Biologia Vegetal da UFV, 36571-000 Viçosa-MG, <rmeira@ufv.br>; ${ }^{4}$ Professor do Dep. de Biologia Geral da UFV. 
substâncias e íons (Fahn, 1979; Baker \& Baker, 1983; Durkee, 1983). Quanto à localização, podem ser classificados em florais e extraflorais (Schmid, 1988); os florais são freqüentemente envolvidos na polinização (Erickson \& Garment, 1979; Inouye, 1983; Varadarajan \& Brown, 1988; Kuchmeister et al., 1997), enquanto os extraflorais comumente são visitados por insetos que conferem proteção à planta contra o ataque de herbívoros (Janzen, 1966; Bentley, 1977a, b; Beattie, 1985; Oliveira, 1997). O estudo do envolvimento de visitantes que forrageiam os nectários extraflorais na defesa contra herbivoria em plantas cultivadas pode contribuir com informações para o desenvolvimento de biocontrole de pragas em diversas lavouras (Bentley, 1983).

Pelo menos 68 famílias de angiospermas possuem representantes portadores de nectários extraflorais, sendo estes mais freqüentes entre as dicotiledôneas. A presença de nectários extraflorais em 35 ordens de angiospermas (Elias, 1983), exibindo grande diversidade em seu desenvolvimento ontogenético, indica que essas estruturas se desenvolveram independentemente e em épocas diferentes em várias famílias (Elias, 1983; Vogel, 1997).

Triumfetta semitriloba (Tiliaceae) é uma planta daninha de pastagens, pomares, terrenos baldios e beira de estradas. É conhecida, popularmente, por carrapicho-de-boi, carrapichão, carrapicho-miúdo, junta-nacional, carrapicho-de-linho, guanxuma, carrapicho (PE, SP) e carrapicho-da-calçada. Caracteriza-se por ser perene, de porte subarbustivo, ereta e muito ramificada, com folhas alternas, pecioladas, denso-pubescentes e polimórficas. No Brasil ocorre na Região Sudeste, em parte do CentroOeste, em Santa Catarina e na Bahia (Lorenzi, 1982). O gênero ocorre em toda a América tropical, e a família tem como centro de dispersão o Brasil e a África (Barroso, 1978).

Collevatti et al. (1997, 1998), estudando o comportamento de forrageamento de visitantes florais em $T$. semitriloba, verificaram que os principais agentes polinizadores são abelhas e que o pólen é o principal recurso procurado, embora algumas espécies visitem as flores, principalmente à procura de néctar.

Triumfetta semitriloba possui nectários florais e extraflorais. Os florais se localizam no androginóforo e os extraflorais nos dentes basais do bordo da lâmina da folha, tanto do ramo florífero quanto do ramo vegetativo. Estruturalmente, os nectários são constituídos por uma epiderme secretora formada por tricomas nectaríferos, onde subjacente se localiza um parênquima nectarífero constituído por células relativamente pequenas, com citoplasma denso, pequenos vacúolos e núcleo grande e esférico. A este parênquima chega a vascularização, constituída por xilema e floema (Leitão, 2001). Nectários desse tipo são comuns na ordem Malvales (Cristobal \& Arbo, 1971; Arbo, 1972; Wergin et al., 1975; Fahn, 1979; Sawidis et al., 1987; Sawidis, 1991).

O estudo da anatomia e da ontogenia dos nectários extraflorais de $T$. semitriloba é de importância para a sistemática, por oferecer dados de aplicação taxonômica. O conhecimento do desenvolvimento desses nectários também oferece subsídios para estudos da interação entre $T$. semitriloba e visitantes. O presente trabalho teve como objetivo descrever a ontogenia dos nectários extraflorais de T. semitriloba.

\section{MATERIAL E MÉTODOS}

Foram utilizadas plantas de Triumfetta semitriloba adultas, com aproximadamente um metro de altura, coletadas no campo da Unidade de Estudos em Ecologia de Comunidades (Departamento de Biologia Geral - UFV). As amostras foram obtidas de dentes foliares basais portadores de nectário em folhas do ramo vegetativo.

As folhas foram selecionadas de acordo com o seguinte critério (Figura 1):

- Estádio I - primórdios foliares no ápice do ramo, com $5 \mathrm{~mm}$ de comprimento.

- Estádio II - folhas em expansão, limbo com $12 \mathrm{~mm}$ de comprimento, localizadas a 1-2 nós abaixo das do estádio I.

- Estádio III - folhas caracterizadas pela expansão quase completa, limbo com $80 \mathrm{~mm}$ de comprimento, localizadas a 1-2 nós abaixo das do estádio II.

- Estádio IV - folhas caracterizadas pela completa expansão, limbo com $100 \mathrm{~mm}$ de comprimento e nectários de coloração escura, localizadas a 4-8 nós abaixo das folhas do estádio III. 


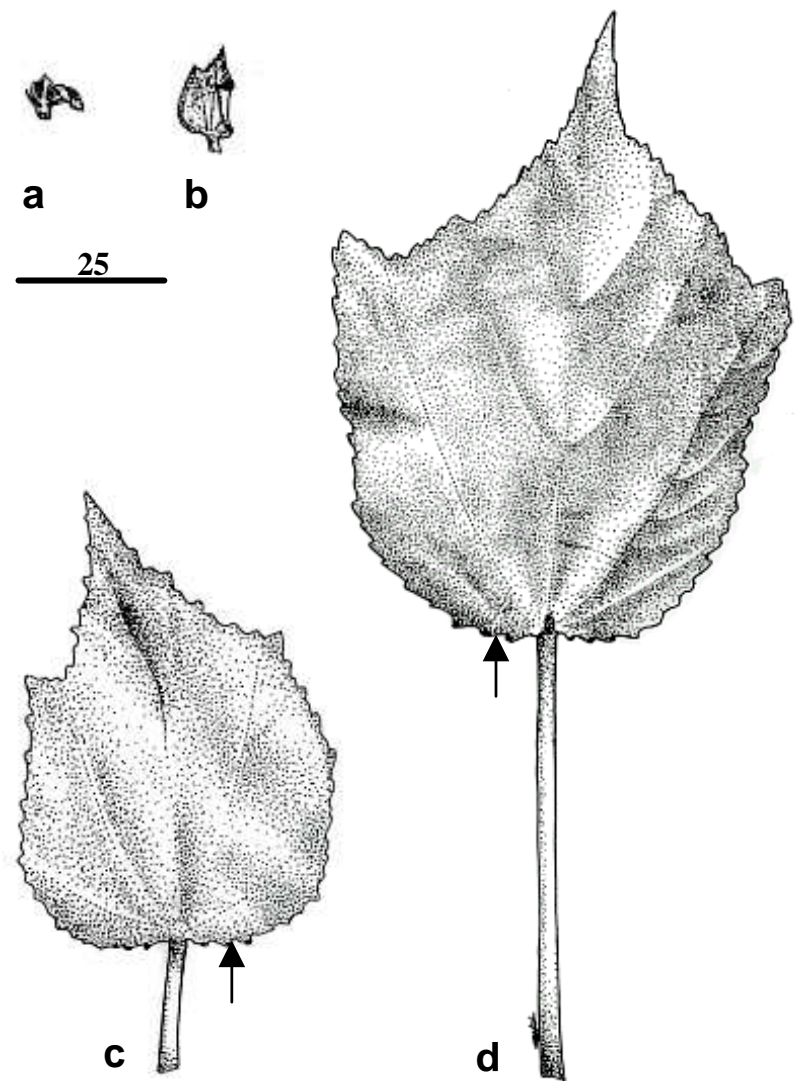

Figura 1 - Esquema de folhas de Triumfetta semitriloba nos quatro estádios de desenvolvimento. a: estádio I; b: estádio II; c: estádio III; d: estádio IV. Escala em milímetros. Seta: nectários)

Para a caracterização anatômica, as amos-

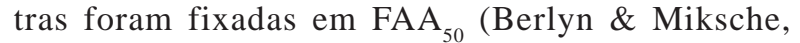
1976), ou em solução contendo glutaraldeído e paraformaldeído (Karnovsky, 1965, modificado), e incluídas em historesina (Historesin Leica) ou parafina. Para verificação de compostos fenólicos, as amostras foram fixadas em solução aquosa de sulfato ferroso $2 \%$ e em formalina 4\%; este teste dispensa tratamentos posteriores (Johansen, 1940). Os blocos foram cortados em um micrótomo rotativo RM 2155 da Leica.

Os cortes de material incluído em parafina ( $8 \mu \mathrm{m}$ de espessura) foram corados com fucsina e azul-de-astra (Roeser, 1972); já aqueles incluídos em historesina (2-4 $\mu \mathrm{m}$ de espessura) foram corados em azul-de-toluidina em tampão McIlvaine pH 4,0 (Vidal, 1977), ou submetidos à reação P.A.S. (Maia, 1979, modificado). As lâminas foram montadas com bálsamo-docanadá (Berlyn \& Miksche, 1976).
$\mathrm{Na}$ análise e documentação fotográfica foi utilizado um fotomicroscópio Olympus AX 70 equipado com sistema fotográfico U-Photo, com uma câmera digital e recurso de contraste de fase e polarização.

\section{RESULTADOS E DISCUSSÃO}

Os nectários de Triumfetta semitriloba estão localizados no ápice dos primeiros três a cinco dentes basais, em cada lado da margem foliar, e podem ser identificados desde o estádio I de desenvolvimento da folha. Não há formação de novos nectários em estádios posteriores. O número de nectários é maior nas folhas que, na maturidade, atingem maiores dimensões e assumem o formato trilobado característico da espécie.

As folhas dos estádios I e II apresentam tamanho relativamente menor que as dos estádios subseqüentes (Figura 1). As folhas dos estádios I, II e III localizam-se em nós muito próximos, estando as folhas dos estádios III, IV e subseqüentes separadas por entrenós relativamente mais longos.

Estádio I: Os nectários no estádio I encontram-se em início de formação, sendo caracterizados por uma concavidade na face adaxial (Figura 2) revestida por uma protoderme pouco diferenciada, com um meristema fundamental subjacente que se diferencia por não apresentar plastídios evidentes (Figura 3). Ao redor da concavidade, as células epidérmicas apresentam-se mais expandidas, sendo freqüente a ocorrência de tricomas tectores nessa região (Figura 2). Podem-se notar vários idioblastos mucilaginosos e tricomas tectores na epiderme fora da concavidade. Ao nectário chegam três terminações vasculares, que se ramificam e coalescem profusamente. Os feixes que vascularizam o nectário ocupam grande parte do mesofilo e são delimitados por bainha parenquimática constituída por células expandidas (Figura 2), cujo conteúdo reagiu positivamente ao teste para compostos fenólicos. Por toda a superfície aérea da planta ocorrem tricomas glandulares clavados pluricelulares, unisseriados ou bisseriados (Figura 4), cujo conteúdo das células da cabeça e do pescoço reagiu com o teste para detecção de compostos fenólicos (Figura 6).

Planta Daninha, Viçosa-MG, v.20, n.3, p.343-351, 2002 


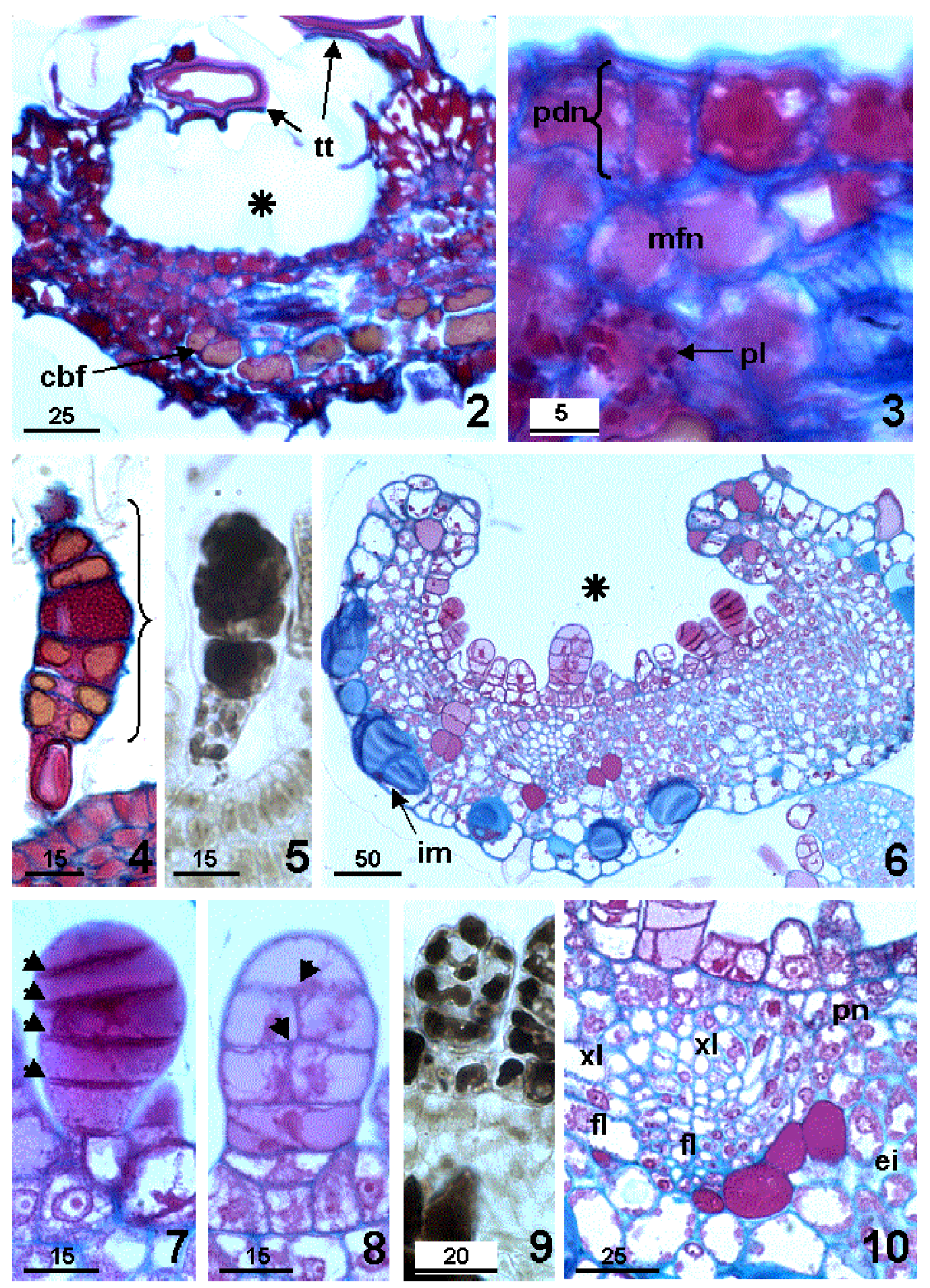

Prancha 1 - Nectários extraflorais e tricomas glandulares de Triumfetta semitriloba. Figura 2 - Nectário em estádio I. cb: célula da bainha do feixe; tt: tricomas tectores; asterisco: concavidade do nectário. Figura 3. Nectário em estádio I. mfn: meristema fundamental do nectário; pdn: protoderme do nectário; pl.: plastídeo em célula não-nectarífera. Figura 4. Tricoma glandular extranectarífero; chave: células da cabeça. Figura 5. Teste para detecção de compostos fenólicos em tricoma glandular extranectarífero. Figura 6. Nectário em estádio II. im: idioblasto mucilaginoso; asterisco: concavidade do nectário. Figura 7. Tricoma nectarífero em estádio II. Cabeças de seta: divisões periclinais. Figura 8. Tricoma nectarífero em estádio II. Cabeças de seta: divisões anticlinais. Figura 9. Teste para detecção de compostos fenólicos em nectário em estádio II. Figura 10. Nectário em estádio II. ei: espaços intercelulares; fl: floema; pn: parênquima nectarífero; xl: xilema. Escala em micrômetros. 

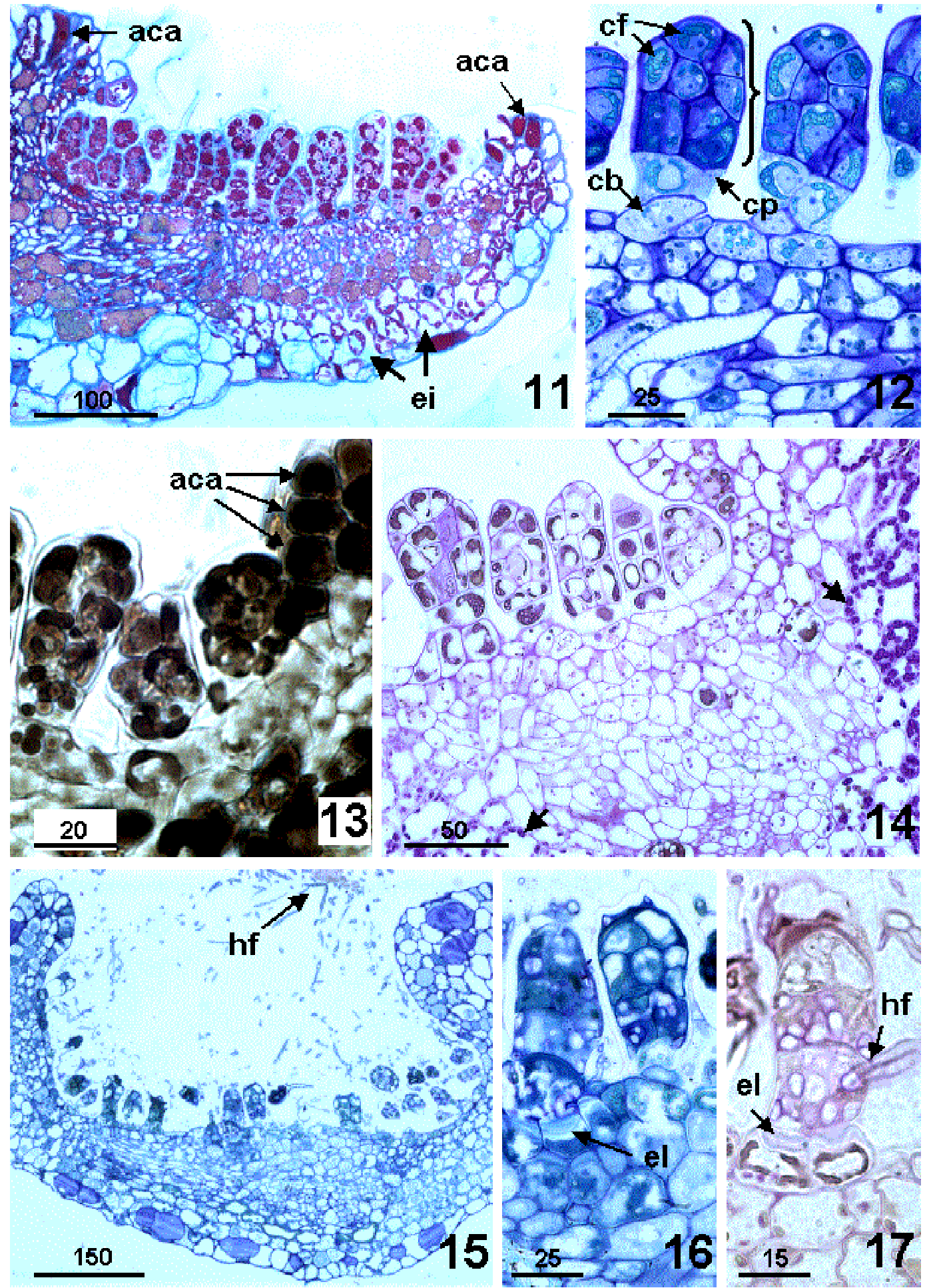

Prancha 2 - Nectários extraflorais de Triumfetta semitriloba. Figura 11. Nectário em estádio III. aca: anel de células avermelhadas; ei: espaços intercelulares. Figura 12. Nectário em estádio III, corado com azul-de-toluidina. cb: célula basal; cf: compostos fenólicos; cp: célula do pescoço; chave: células da cabeça. Figura 13. Teste para detecção de compostos fenólicos em nectário em estádio III. aca: anel de células avermelhadas. Figura 14. Reação ao P.A.S. em nectário em estádio III. Cabeças de seta: grânulos positivos ao teste. Figura 15. Nectário em estádio IV. hf: hifas. Figura 16. Nectário em estádio IV. el: espessamento lamelar. Figura 17. Tricoma nectarífero em estádio IV. hf: hifas. Escala em micrômetros. 
Estádio II: À vista desarmada, a margem da concavidade do nectário tem coloração avermelhada. Esta concavidade se apresenta mais aprofundada (Figura 6) que no estádio anterior. $\mathrm{Na}$ epiderme da concavidade começam a se diferenciar os tricomas nectaríferos (Figura 6). Os tricomas encontram-se em diferentes fases de desenvolvimento (Figuras 6, 7 e 8) e são formados a partir de divisões periclinais das células protodérmicas (Figura 7), seguidas por divisões anticlinais nas células apicais (Figura 8). As células desses tricomas apresentam corpos com formato irregular, que reagem positivamente ao teste de detecção de compostos fenólicos (Figura 9). Fora da concavidade, as células epidérmicas apresentam-se expandidas, sendo comum a ocorrência de idioblastos mucilaginosos em ambas as faces (Figura 6). No nectário, as células subjacentes à epiderme adaxial côncava apresentam formato cúbico, arranjo compacto, citoplasma denso e núcleo relativamente grande, constituindo um parênquima nectarífero (Figura 10). As demais células parenquimáticas encontram-se mais expandidas e vacuolizadas e se dispõem mais frouxamente, delimitando espaços intercelulares conspícuos (Figura 10). Os feixes vasculares do nectário exibem maior grau de desenvolvimento, em comparação com o estádio anterior. Em algumas preparações foram visualizadas terminações vasculares chegando até a camada do parênquima nectarífero em contato com a epiderme secretora (Figura 10).

Estádio III: Os nectários encontram-se totalmente formados (Figura 11) e a secreção é evidente. Os tricomas nectaríferos são numerosos e recobrem totalmente a concavidade (Figura 11). São formados por 1 ou 2 células basais, 1 ou 2 células no pescoço e por uma cabeça que é multisseriada, com 3 a 4 camadas de células (Figura 11). Os compostos fenólicos encontrados nas células do pescoço e da cabeça desses tricomas localizam-se entre o núcleo e a periferia destas células (Figuras 12 e 13). A concavidade do nectário é margeada por um anel de células de coloração avermelhada, cujo conteúdo se cora de verde pelo azul-de-toluidina, e reage positivamente ao teste para detecção de compostos fenólicos (Figura 13). Em algumas preparações, pode-se notar a presença de hifas fúngicas na concavidade. As células do parênquima clorofiliano, subjacentes à epiderme abaxial, se mostram mais expandidas e vacuolizadas que no estádio anterior, delimitando espaços intercelulares maiores (Figura 12), e apresentam pequenos grânulos elípticos que reagem positivamente ao P.A.S. (Figura 14). Quanto às outras características, não foram notadas diferenças em relação ao estádio anterior.

Estádio IV: À vista desarmada, o nectário apresenta coloração mais escura. Os tricomas nectaríferos apresentam morfologia alterada (Figuras 15 e 16). Suas células caracterizamse pela desorganização do citoplasma e pela degeneração do núcleo (Figura 16). Na parede periclinal externa das células do parênquima nectarífero ou das células basais observam-se espessamentos de aspecto lamelado (Figuras 16 e 17). Já na parede das células da cabeça e do pescoço verifica-se retração (Figura 16). A epiderme secretora torna-se totalmente recoberta por hifas (Figura 15), que podem penetrar nos tricomas nectaríferos (Figura 17). As células do parênquima nectarífero apresentam um vacúolo maior e paredes enrugadas, sendo comum a ocorrência de células com o citoplasma desorganizado (Figura 16).

O desenvolvimento ontogenético dos nectários extraflorais de $T$. semitriloba inicia-se precocemente. A diferenciação e o início de atividade de secreção precoce também são comuns a outros tipos de estruturas secretoras (Fahn, 1979; Vermeer \& Peterson, 1979; Maksymowych \& Maksymowych, 1982). Os nectários de $T$. semitriloba em estádio de secreção encontram-se em folhas em estádio III, localizadas próximas às folhas dos estádios anteriores e ao ápice meristemático. Tendo em vista a importância dos nectários em interações mutualísticas com insetos que conferem proteção à planta (Keeler, 1981; Pemberton \& Lee, 1996; Freitas \& Oliveira; 1996), é de se esperar que o desenvolvimento precoce dos nectários seja um atrativo para as formigas ao ápice do ramo, uma região delicada constituída por estruturas em desenvolvimento, mais sujeitas aos danos causados por herbivoria.

As células dos tricomas dos nectários extraflorais de $T$. semitriloba apresentam um vacúolo cujo conteúdo se cora de verde devido ao azul-de-toluidina e reage positivamente ao teste para detecção de compostos fenólicos. 
Essas estruturas são observadas desde o estádio II de desenvolvimento, e a sua permanência durante o estádio secretor é um indício de que não estão envolvidas diretamente na secreção do néctar. Estruturas semelhantes são observadas em outros nectários encontrados entre as Malvales, como em Gossyipium hirsutum Cav. (Eleftheriou \& Hall, 1983) e Hibiscus rosasinensis Lin. (Sawidis et al., 1989; Sawidis, 1991), porém não são discutidas as funções desses compostos. As células dos tricomas secretores encontrados por toda a superfície aérea de T. semitriloba também apresentam um vacúolo que contém compostos fenólicos. Essa característica pode ser indício de uma origem comum dos referidos tricomas.

Compostos fenólicos são um grupo de substâncias que têm demonstrado importante função na interação de plantas com animais. São substâncias adstringentes que promovem impalatabilidade para herbívoros e fitófagos (Fahn, 1979; Roshchina \& Roshchina, 1993; Carvalho et al., 2000). Também têm atividade antibacteriana e anfifúngica, particularmente contra organismos fitopatogênicos (Bruneton, 1999). A presença desses compostos nas células da cabeça dos tricomas dos nectários extraflorais de $T$. semitriloba pode estar relacionada com a proteção desses tricomas contra lesão pelas formigas durante o seu forrageamento, assim como contra a penetração de hifas, uma vez que estes compostos ocorrem entre o núcleo e a parede das células que delimitam o tricoma.

No presente trabalho não foram encontradas modificações na cutícula que recobre as células apicais dos tricomas nectaríferos ao longo de seu desenvolvimento, até o estádio secretor. O acúmulo de néctar entre a cutícula e as paredes das células da epiderme secretora, bem como sua posterior liberação por rompimento da cutícula, é amplamente relatado na literatura (Durkee, 1982, 1983; Mohan \& Inamdar, 1986; Davis et al., 1988; Subramanian \& Inamdar, 1989). Quando não ocorre rompimento de cutícula, podem existir poros (Findlay \& Mercer, 1971; Fahn, 1979; Sawidis et al., 1989; Machado, 1999) ou regiões de maior permeabilidade na cutícula (Roshchina \& Roshchina, 1993).

Desde o início do desenvolvimento, as células do parênquima nectarífero apresentaram plastídios inconspícuos. Essas organelas não foram observadas nos tricomas nectaríferos, sendo sua escassez um indício de que provavelmente os plastídios não atuam de forma significativa na secreção do néctar extrafloral de T. semitriloba. É necessário um estudo ultra-estrutural da secreção dos nectários de T. semitriloba para melhor compreensão do envolvimento de organelas na secreção do néctar e nos processos de sua eliminação através da cutícula.

Após a secreção, observa-se uma mudança na coloração dos nectários extraflorais de T. semitriloba devido ao azul-de-toluidina, se comparado com os estádios anteriores. Essa alteração deve-se a uma mudança de radicais aniônicos nas células nectaríferas, possivelmente em virtude da liberação do conteúdo vacuolar. Em Ancistrocactus scheeri Britton \& Rose (Cactaceae) ocorre abscisão de todos os tecidos do nectário após a sua atividade de secreção (Mauseth, 1982). Em T. semitriloba não foi verificada abscisão do nectário foliar senescente, mas se observou diminuição no número de tricomas e espessamento, de aspecto lamelar, na parede periclinal externa de suas células basais e das células do parênquima nectarífero, o que pode ocasionar a queda da cabeça do tricoma. Esse espessamento também pode ser uma resposta contra a invasão de hifas aos tecidos internos do nectário.

Uma das diferenças mais marcantes observadas entre os nectários extraflorais senescentes e em atividade de secreção foi a grande presença de hifas, recobrindo totalmente o nectário senescente, ao passo que nos nectários em atividade a sua ocorrência é muito mais restrita. Em Citharexylum myrianthum Cham. (Verbenaceae), formigas Camponotus provavelmente participam da remoção de hifas dos nectários extraflorais em atividade, sendo encontradas hifas apenas sobre os nectários senescentes (Machado, 1999). Como T. semitriloba é visitada por formigas Camponotus em Viçosa-MG (Rodrigues, 1997), provavelmente estas formigas também removam hifas sobre os seus nectários extraflorais em atividade.

\section{AGRADECIMENTOS}

Às servidoras do Laboratório de Anatomia Vegetal do Departamento de Biologia Vegetal - 
UFV, Rosane Cruz Portugal e Zilda Alzira Soares, pelo apoio técnico, ao $\mathrm{CNPq}$ e à CAPES, pela bolsa concedida, e à FAPEMIG, pelo apoio financeiro concedido ao projeto.

\section{LITERATURA CITADA}

ARBO, M. M. Estructura y ontogenia de los nectarios foliares del género Byttneria (Sterculiaceae). Darwiniana, v. 17, p. 104-158, 1972.

BAKER, H. G.; BAKER, I. A brief historical review of the chemistry of floral nectar. In: BENTLEY, B.; ELIAS, T. (Eds.). The biology of nectaries. New York: Columbia University Press, 1983. p. 126-152.

BARROSO, M. B. Sistemática de angiospermas do Brasil. São Paulo: Livros Técnicos e Científicos, 1978. v. 1. 309 p.

BEATTIE, A. J. The evolutionary ecology of ant-plant mutualisms. New York: Cambridge University Press, 1985. $182 \mathrm{p}$.

BENTLEY, B. L. Extrafloral nectaries and protection by pygnacious bodyguards. Ann. Rev. Ecol. Syst., v. 8, p. 407-427, 1977a.

BENTLEY, B. L. The protective function of ants visiting the extrafloral nectaries of Bixa orellana L. (Bixaceae). J. Ecol., v. 65, p. 27-38, 1977b.

BENTLEY, B. L. Nectaries in agriculture, with an emphasis on the tropics. In: BENTLEY, B., ELIAS, T.S. (Eds.) The biology of nectaries. New York: Columbia University Press, 1983. p. 204-222.

BERLYN, G. P.; MIKSCHE, J. P. Botanical microtechnique and cytochemistry. Ames: Iowa State University Press, 1976. 326 p.

\section{BRUNETON, J. Pharmacognosy-phytochemistry} medicinal plants. Lavousier Publishing, 1999. 119 p.

CARVALHO, J. C. T.; GOSMANN, G.; SCHENKEL, E. P. Compostos fenólicos simples e heterosídicos. In: SIMÕES, C. M. O.; SCHENKEL, E. P.; GOSMANN, G.; MELLO, J. C. P.; MENTZ, L. A.; PETROLVICK. (Eds.) Farmacognosia: da planta ao medicamento. Florianópolis: Universidade Federal do Rio Grande do Sul, 2000. p. 451-469.

COLLEVATTI, R. G.; CAMPOS, L. A. O.; SCHOEREDER, J. H. Foraging behaviour of bee pollinators on the tropical weed Triumfetta semitriloba: departure rules from flower patches. Ins. Soc., v. 44, p. 345-352, 1997.

COLlEVATTI, R. G.; CAMPOS, L. A. O.; SILVA, A. F. Pollination ecology of the tropical weed Triumfetta semitriloba Jacq. (Tiliaceae), in the south-eastern Brazil. R. Bras. Biol., v. 58, p. 383-392, 1998.

Planta Daninha, Viçosa-MG, v.20, n.3, p.343-351, 2002
CRISTOBAL, C. L.; ARBO, M. M. Sobre las especies de Ayenia (Sterculiaceae) con nectarios foliares. Darwiniana, v. 16, p. 603-612, 1971.

DAVIS, A. R.; PETERSON, R. L.; SHUEL, R. W. Vasculature and ultrastructure of the floral and stipular nectaries of Vicia faba (Leguminosae). Can. J. Bot., v. 66, p. 1435-1448, 1988.

DURKEE, L. T. The floral and extra-floral nectaries of Passiflora. II. The extra-floral nectary. Am. J. Bot., v. 69, p. 1420-1428, 1982.

DURKEE, L. T. The ultrastructure of floral nectaries. In: BENTLEY, B.; ELIAS, T. S. (Eds.) The biology of nectaries. New York: Columbia University Press, 1983. p. 1-29.

ELEFTHERIOU, E. P.; HALL, J. L. The extrafloral nectaries of cotton. I. Fine structure of the secretory papillae. J. Exp. Bot., v. 34, p. 103-119, 1983.

ELIAS, I. Extrafloral nectaries: their structure and distribution. In: BENTLEY, B.; ELIAS, T.S. (Eds.) The biology of nectaries. New York: Columbia University Press, 1983. p. 174-203.

ERICKSON, E. H.; GARMENT, M. B. Soya-bean flowers: nectary ultrastructure, nectar guides, and orientation on the flower by foraging honeybees. J. Apic. Res., v. 18, p. 3-11, 1979.

FAHN, A. Secretory tissues in plants. New York: Academic Press, 1979. 302 p.

FINDLAY, N.; MERCER, F. V. Nectar prodution in Abutilon I. Moviment of nectar through the cuticle. Aust. J. Biol. Sci., v. 24, p. 647-656, 1971.

FREITAS, A. V. L.; OLIVEIRA, P. S. Ants as selective agents on herbivore biology: effects on the behaivor of a non-myrmecophilus butterfly. J. Animal Ecol., v. 65, p. 205-210, 1986.

INOUYE, D. W. The ecology of nectar robbing. In: BENTLEY, B.; ELIAS, T. S. (Eds.) The biology of nectaries. New York: Columbia University Press, 1983. p. $153-173$.

JANZEN, D. H. Coevolution of mutualism between ants and acacias in Central America. Evolution, v. 20, p. 249$275,1966$.

JOHANSEN, D. A. Plant microtechnique. New York: McGraw-Hill Book, 1940. 523 p.

KARNOVSKY, M. J. A formaldehyde-glutaraldehyde fixative of high osmolality for use in electron microscopy. J. Cell Biol., v. 27, p. 137-138, 1965. 
KEELER, K. H. A model of selection for cacultative nonsymbiotic mutualism. Am. Nat., v. 118, p. 488-498, 1981.

KUCHMEISTER, H.; GOTTSBERGER, I. S.; GOTTSBERGER, G. Flowering, pollination, nectar standig crop, and nectaries of Euterpe precatoria (Arecaceae), an Amazonian rain forest palm. Plant Syst. Evol., v. 206, p. 71-97, 1997.

LEITÃO, C. A. E. Caracterização estrutural dos nectários de Triumfetta semitriloba Jacq. (Tiliaceae). Viçosa-MG: Universidade Federal de Viçosa, 2001. 69 p. Dissertação (Mestrado em Botânica) - Universidade Federal de Viçosa, 2001.

LORENZI, H. Plantas daninhas do Brasil: terrestres, aquáticas, parasitas, tóxicas e medicinais. Nova Odessa: Editora, 1982. 440 p.

Machado, S. R. Estrutura e desenvolvimento de nectários extra-florais de Citharexylum mirianthum Cham.

(Verbenaceae). Botucatu: UNESP, 1999. 113 p. Tese

(Livre Docência ) - Universidade Estadual Paulista, 1999.

MAIA, V. Técnica histológica. São Paulo: Atheneu, 1979. $246 \mathrm{p}$.

MAKSYMOWYCH, R.; MAKSYMOWYCH, A. B. Petiole development and xylem differentiation in Xanthium represented by the plastochron index. Am. J. Bot., v. 69, p. 23-30, 1982.

MAUSETH, J. D. Development and ultrastructure of extrafloral nectaries in Ancistrocactus scheeri (Cactaceae). Bot. Gaz., v. 143, p. 273-277, 1982.

MOHAN, J. S. S.; INAMDAR, J. A. Ultrastructure and secretion of extrafloral nectaries of Plumeria rubra L. Ann. Bot., v. 57, p. 389-401, 1986.

OLIVEIRA, P. S. The ecological function of extrafloral nectaries: herbivore deterrence by visiting ants and reproctive output in Caryocar brasiliense (Caryocaraceae). Funct. Ecol., v. 11, p. 323-330, 1997.

PEMBERTON, R. W.; LEE, J. The influence of extrafloral nectaries on parasitism of an insect herbivore. Am. J. Bot., v. 83, p. 1187-1194, 1996.

RODRIGUES, L. L. Efeito da presença de formigas associadas às glândulas de Triumfetta semitriloba Jacq. (Tiliaceae) sobre o sucesso reprodutivo da planta. Monografia de Graduação. Viçosa: Universidade Federal de Viçosa, 1997. 67 p.
ROESER, K. R. Die nadel der schwarzkiefer. Massenprodukt und kunstwerk der natur. Mikrokosmos, v. 61, p. 33-36, 1972.

ROSHCHINA, V. V.; ROSHCHINA, V. D. The excretory function of higher plants. Berlin: Springer-Verlag, 1993. $314 \mathrm{p}$.

SAWIDIS, T. A histochemical study of nectaries of Hibiscus rosa-sinensis. J. Exp. Bot., v. 42, p. 1477-1487, 1991.

SAWIDIS, T.; ELEFTHERIOU, E. P.; TSEKOS, I. The floral nectaries of Hibiscus rosa-sinensis I. Development of the secretory hairs. Ann. Bot., v. 59, p. 643-652, 1987.

SAWIDIS, T.; ELEFTHERIOU, E. P.; TSEKOS, I. The floral nectaries of Hibiscus rosa-sinensis III. A morphometric and ultrastructural approach. Nord. J. Bot., v. 9, p. 63-71, 1989.

SCHMID, R. Reproductive versus extra-reprodutives nectaries - historical perspective and terminological recommendations. Bot. Rev., v. 54, p. 179-232, 1988.

SUBRAMANIAN, R. B.; INAMDAR, J. A. The structure, secretion and biology of nectaries in Tecomaria capensis Thunb (Bignoniaceae). Phytomorphology, v. 39, p. 69-74, 1989.

VARADARAJAN, G. S.; BROWN, G. K. Morphological variation of some floral features of the subfamily Pitcairnioideae (B romeliaceae) and their significance in pollination biology. Bot. Gaz., v. 149, p. 82-91, 1988.

VERMEER, J.; PETERSON, R. L. Glandular trichomes on the inflorescence of Chrysanthemum morifolium $\mathrm{cv}$. dramatic (Compositae). I. Development and morphology. Can. J. Bot., v. 57, p. 705-713, 1979.

VIDAL, B. C. Acid glycosaminoglycans and endochondral ossification: microespectrophotometric evaluation and macromolecular orientation. Cell Mol. Biol., v. 22, p. 45-64, 1977.

VOGEL, S. Remarkable nectaries: structure, ecology, organophyletic perspectives I. Substitutive nectaries. Flora, v. 192 , p. $305-333,1997$.

WERGIN, W. P. et al. Ultrastructure of the subglandular cells from the foliar nectaries of cotton in relation to the distribution of plasmodesmata and the symplastic transport of nectar. Am. J. Bot., v. 62, p. 842-849, 1975. 